\title{
A Interação Entre Aluno e Conteúdo Material Didático Impresso na Educação a Distância
}

\section{Teaching Materials Printed in Distance Education Interaction Between Student and Content}

\begin{abstract}
Resumo: Este trabalho apresenta as contribuições e as limitações do uso do material didático impresso no processo de aprendizagem em educação a distância, bem como discorre sobre a potencialidade desse tipo de material na formação do aluno autônomo. Através de uma pesquisa bibliográfica, investigamos a relação entre a elaboração do material didático impresso e a promoção da autonomia do aluno. Concluímos que o material didático deve despertar a automotivação e ter como base o paradigma da autoformação e autonomia. Propomos a criação de materiais didáticos que impeçam um ensino mnemônico para garantir o desenvolvimento de competências necessárias para o estabelecimento de uma atitude autônoma do aluno na interação com o conhecimento.

Palavras-chave: Aprendizagem. Autonomia. Material didático impresso.
\end{abstract}

Abstract: This paper presents the contributions and limitations of using textbooks printed in the learning process in distance education, and discuss the potential of this type of material in the formation of the autonomous learner. Through a literature search, we investigated the relationship between the preparation of printed textbooks and the promotion of learner autonomy. We conclude that the courseware should arouse self-motivation and based on the paradigm of self-education and autonomy. We propose the creation of teaching materials that prevent teaching mnemonic to ensure the development of skills necessary for the establishment of an autonomous attitude of student interaction with knowledge.

Keywords: Learning. Autonomy. Printed educational material.

SILVA, Andréa Villela Mafra da. A Interação Entre Aluno e Conteúdo Material Didático Impresso na Educação a Distância. Informática na Educação: teoria e prática, Porto Alegre, v. 17, n. 2, p. 89-97, jul./dez. 2014.

\author{
Andréa Villela Mafra da Silva \\ Universidade Federal do Rio de Janeiro
}

\section{Introdução}

A presente investigação consiste no trabaIho final do curso de especialização em Planejamento, Implementação e Gestão da Educação a Distância (PIGEAD) desenvolvido pelo Laboratório de Novas Tecnologias de Ensino (LANTE) da Universidade Federal Fluminense (UFF). Este foi desenvolvido como uma pesquisa sobre o papel, a função e os aspectos fundamentais do material didático impresso na educação a distância e foi realizado parte em grupo e parte individualmente, sob a orientação da professora Maria Cordeiro de Farias Gouveia Matos. Este artigo apresenta a parte individual, de minha autoria, que discute a questão da autonomia do aluno no uso do material didático impresso em cursos a distância. A proposta é perceber se estes materiais são elaborados, levando-se em conta o potencial 
de criticidade dos alunos, de forma a permitir a sua atuação sobre o conhecimento.

O material didático impresso é a mídia mais comum utilizada na Educação a Distância e assume várias formas, incluindo livros didáticos, manuais e guias de estudo (MOORE; KEARSLEY, 2010). Ainda de acordo com Moore e Kearsley (2010), não existe tecnologia melhor que o material didático impresso para comunicar as metas e os objetivos dos conteúdos de ensino. De fato, esse tipo de material possibilita ao aluno refletir e analisar criticamente a mensagem veiculada pelo texto. Ademais, o material didático impresso é "[...] invariavelmente criado para atender à lógica e à estrutura da disciplina [...]" (MOORE; KEARSLEY, 2010, p. 78), no entanto, a motivação é uma variável importante no aprendizado a distância. Por essa razão, o material impresso deve motivar o aluno ao estudo e sobretudo, possibilitar o desenvolvimento de capacidades de análises e sínteses para que estes se apropriarem de competências reflexivo-críticas e de mediação de conhecimentos.

O texto impresso transmite de modo eficiente grandes volumes de informação e os alunos podem ler esse material em qualquer ocasião e com a frequência desejada (MOORE; KEARSLEY, 2010). A elaboração do material impresso deve prever tratar a reflexão epistemológica sobre os conteúdos ensinados, de forma a levar o aluno a se responsabilizar com sua aprendizagem e com os procedimentos que, quando postos em ação, produzem conhecimentos válidos. Importante acrescentar que, alunos com menor grau de autonomia no processo de ensino e aprendizagem, necessitam de um material didático impresso que atenda às suas necessidades e limitações e que, sobretudo, seja adaptado para os contextos de educação a distância.
Cabe destacar que este trabalho apresenta as contribuições e as limitações, no processo de aprendizagem em educação a distância, do material didático obtido de forma impressa. O material disponibilizado online, que pode ter conteúdo similar ao material impresso, requer leitura em tela de computador, conexão com a internet e um navegador na web.

\section{Desenvolvimento}

A influência da tradição autoritária nas estruturas das instituições de ensino faz com que a educação deixe de ser uma autoformação do indivíduo para ser uma transmissão automática de saberes memorizados e sem significado. Nas bases da educação autoritária percebemos um ensino mnemônico que impede um comportamento autônomo do aluno. O aluno é visto como um espectador do processo de ensino e aprendizagem com uma atuação passiva frente ao conhecimento.

Nos termos de Valente e Moran (2011, p. 13), "[...] uma formação totalmente baseada na memorização não é capaz de preparar pessoas para atuarem e sobreviverem na sociedade do conhecimento". Diferentes autores, ao discutirem questões de ensino e aprendizagem colocam que o conhecimento deve ser visto de forma interativa, de maneira que todos participem da sua construção em um clima de autonomia e colaboração (SILVA, 2009). A apropriação do conhecimento exige meios favoráveis que auxiliem o aluno a investigar, problematizar e compreender o objeto de estudo. Em contraponto, a essa educação pautada no ensino mnemônico, destacamos as práticas em EaD que devem buscar propostas pedagógicas que possibilitem um comportamento autônomo do aluno frente ao conhecimento. 
Valente e Moran (2011) afirmam que a aprendizagem efetiva e significativa deve partir de oportunidades de construção do conhecimento que privilegie uma ação autônoma do aprendiz. Nesse caso, é por intermédio do uso do material didático impresso nos cursos a distância que o trabalho com o conteúdo /conhecimento poderá promover a aprendizagem autônoma do aprendiz. Reafirmar a importância da utilização do material didático impresso no curso a distância, nas palavras de Preti significa constatar que:

a) Trata-se de tecnologia que não é nova, mas que, ainda, tem espaço garantido numa sociedade em que tecnologias novas se tornam cada vez mais populares e sedutoras $[\ldots]$;

b) Tem crescido enormemente a indústria de material impresso, indicando que o 'fim do livro' está longe de acontecer;

c) É a tecnologia que faz parte de nossa formação escolar (e dos estudantes), do nosso campo profissional [...];

d) $\mathrm{Na} \mathrm{EaD}$, ainda, predomina o uso dessa tecnologia por ser mais acessível;

e) As Instituições que atuam na EaD estão em processo crescente de produção de material didático específico para os cursos em oferta (PRETI, 2009, p. 1).

Nessa direção, percebemos que a educação a distância pode possibilitar uma aprendizagem significativa, na medida em que o aluno é levado a participar ativamente do processo de aprender ao utilizar um material didático bem elaborado e com qualidade gráfica, de ilustrações e conteúdo, em acordo com o projeto pedagógico do curso. Isto significa dizer que, na educação a distância, o aluno pode exercer a autonomia na sua ação frente ao conhecimento. Ele será o responsável pela gerência do tempo de estudo e pela assimilação do conteúdo de ensino. Mas, para que esta ação autô- noma se manifeste, alguns elementos na EaD são considerados importantes: a atuação dos professores tutores, o bom funcionamento da plataforma de ensino e um material didático impresso eficiente. Sobre o material didático, importante consideração a se fazer é que os alunos podem utilizá-lo em qualquer ocasião e com a frequência desejada, facilitando o desenvolvimento de um comportamento autônomo frente ao conhecimento (MOORE; KEARSLEY, 2010).

Considerado como elemento fundamental na produção, circulação e apropriação de conhecimentos, o material didático impresso pode indicar a qualidade do processo de ensino e aprendizagem do curso a distância. É em Barreto (2007) que nos apoiamos para evidenciar que o material didático deve facilitar a aprendizagem de grandes e pequenas unidades de conteúdo, em seus níveis de complexidade. $\mathrm{O}$ modo como o material didático impresso é elaborado e posteriormente utilizado deve ter como finalidade "[...] proporcionar informações básicas imprescindíveis para a compreensão do conteúdo [...]" (MOORE; KEARSLEY, 2010, p. 134) para que o aluno, de forma autônoma, "[...] faça suas próprias descobertas e organize aquilo que aprendeu." (MOORE; KEARSLEY, 2010, p. 134)

O conceito de autonomia no processo de ensino e aprendizagem implica que os alunos "[...] assumam a responsabilidade por criar significado a partir do conteúdo, assimilando ou incluindo novas ideias e conceitos em suas estruturas de conhecimento existentes." (MOORE; KEARSLEY, 2010, p. 246)

Quando tratamos de analisar no debate educativo a distância a construção da autonomia do aluno, estamos evidenciando uma preocupação com o papel da educação formal e a maneira como o individuo constrói o conheci- 
mento. Autonomia é um dos conceitos básicos da socialização e pode ser entendida como a capacidade de agir por si e de formular juízos morais independentes (SILVA, 2009). Neste sentido, pode ser considerada uma conquista individual que permite tomadas de decisão responsáveis e um olhar crítico frente ao conhecimento.

A eficácia do material didático impresso também depende do tipo de concepção educativa no contexto do aprendizado a distância. Sabemos que ao longo do tempo várias experiências educativas, com concepções de educação distintas e diversificadas, foram surgindo para tentar dar conta de uma formação educacional que contemplasse o individuo em sua totalidade, algumas semelhantes e outras distintas entre si. Entretanto, consideramos que sempre é importante elaborar um currículo que apresente como objetivo principal oferecer ao aluno não apenas o conhecimento científico, mas também habilidades capazes de contribuir para o desenvolvimento de seu autoconhecimento e autonomia. Sobre autonomia, Vieira (1997) afirma que é a capacidade para refletir criticamente, tomar decisões e agir com independência, conforme discutimos anteriormente. Ainda em Vieira (1997), a capacidade para a autonomia será demonstrada tanto pela maneira como o aluno aprende quanto pelo modo como aplica em outros contextos o conhecimento adquirido. Para Belloni (1999, p. 84) autonomia significa "[...] autodirecionamento e autodeterminação no processo de educação."

Ao tratarmos de autodirecionamento no processo de educação, por vezes, percebemos o aluno da EaD em um processo solitário de aprendizagem. Assim, necessitará de certo grau de autonomia para participar do curso sem a presença física do professor e deverá perceber o material didático e outros recursos mediáticos como suporte a seu estudo independente. Deste modo, reforçamos a ideia de que a linguagem utilizada nos materiais impressos para a Educação a Distância tem importância fundamental por garantir a atenção, a motivação e a interatividade em um meio de comunicação unidirecional (BARRETO, 2007), permitindo a autonomia de aprendizagem.

Pensando assim, na concepção do material impresso as características culturais, didático e pedagógico, sobretudo motivacionais são consideradas para que o público alvo, ao qual o recurso se destina, seja atendido em suas especificidades. Considerando os desafios da EaD, sugere Silva, que o professor descobre-se autor de conteúdos pedagógicos, ou seja, autor de materiais didáticos que "[...] precisam desenvolver competências comunicativas e priorizar uma abordagem dialógica na produção textual" (SILVA, 2003, p. 335). É, pois, fundamental refletir sobre o material didático impresso para EaD para ressignificar a prática pedagógica e para que este material se constitua como um apoio ao processo de aprendizagem do aluno, ancorado na autonomia.

Os benefícios de tal reflexão resultariam na compreensão de que o material didático em EaD deve favorecer a interação, potencializar o processo educacional e promover a autonomia do aluno através do autoestudo. Aqui também caberia repensar a questão da autoria no material didático para EaD e refletir sobre a importância da equipe disciplinar no planejamento e concepção do material didático. Outro item que merece destaque é perceber que o MDI é um canal de comunicação entre alunos, tutores e professores conteudistas. Os recursos gráficos do material facilitam a usabilidade e navegação na plataforma de ensino e estimulam a pesquisa científica através dos links que usualmente são disponibilizados no 
material didático. Dado que merece atenção é que o MDI deve permitir o estabelecimento de relações entre o conteúdo impresso do material e o que está posto no ambiente virtual de aprendizagem. Reconhecemos que essas reflexões precisam ser constituídas na elaboração do MDI para que efetivamente ajudem na construção de uma real autonomia do aluno. Na ausência dessa decisão de reflexão esbarraríamos em materiais elaborados de forma incorreta e em desacordo com uma proposta de ensino voltada para a autoformação e autonomia do sujeito que aprende.

De acordo com a literatura consultada, um dado que merece destaque e carece de reflexão é que a maioria dos alunos desiste do curso a distância ao perceber que o conteúdo disponibilizado no MDI é irrelevante e pouco contribui para sua formação. Diferentes autores afirmam que os MDI dos cursos a distância, de modo geral, são de baixa qualidade, elaborados de forma econômica e apresentam um volume grande de conteúdo a ser aprendido em desacordo com o tempo de duração do curso. Desta forma, despertam pouco interesse no estudante e, portanto dificultam a aprendizagem a partir dele, inviabilizando o estudo autônomo. No que se refere ao desempenho do aluno, a habilidade para ler e escrever é considerado um pré-requisito essencial para o uso correto do material impresso por exigir maior atenção automotivada (MOORE; KEARSLEY, 2010).

\subsection{Processo Educativo: a Conver- sação Didática Guiada de Holmberg}

O material didático impresso é a mídia mais empregada, como apoio ao estudo, na educação a distância, independentemente de qualquer outra tecnologia que o curso adote e quem o elabora deve ter como foco o incentivo ao aprendizado autodirigido (MOORE; KEARSLEY, 2010). Nessa circunstância, a elaboração do MDI e os elementos presentes em um sistema de educação a distância, como a interação, o grau de maturidade do aluno, a plataforma de ensino e o gerenciamento do curso, são fundamentais para que o aprendiz possa atingir autonomia e autoformação independente.

Holmberg (1995) considera que uma das metas do ensino a distância é ajudar o aluno a atingir autonomia. Parte do pressuposto que o pensamento em voz alta, o processamento elaborado de texto e a leitura em silêncio são considerados processos de comunicação. A aplicação destes processos no desenvolvimento de materiais pedagógicos impressos, teria como consequência a sua adaptabilidade aos princípios da Conversação Didática Guiada, originando uma comunicação entre o aluno e o autor dos materiais, bem como uma comunicação do aluno consigo mesmo. Para buscar a eficiência no processo educativo na EaD, a Conversação Didática Guiada, termo cunhado por Holmberg (1995), ilustra a relação que neste trabalho discutimos, ou seja, autonomia do aluno e o uso do material didático impresso, digo, a interação entre aluno e conteúdo. Segundo Holmberg (1995, p. 43), a motivação do aluno perpassa na "[...] relação pessoal entre os que ensinam e aqueles que aprendem promovendo o prazer de estudar pelo uso de materiais bem preparados [...]" e adequados a proposta filosófica do curso. Para Holmberg (1995), a aprendizagem individual é responsável pelo progresso educativo seguindo o ritmo que cada um (aluno) impõe a seu processo de aprender. Partindo da premissa da efetividade do ensino, este autor destaca alguns elementos que são considerados prioritários para o 
sucesso da aprendizagem. Dentre eles, o sentimento de cooperação e argumentação, que se dá através da conversa mediada, é elencado em primeiro lugar. A teoria de Holmberg se sustenta em pressupostos como:

1. A interpersonalização do processo de ensino aprendizagem promove o prazer e a motivação pelo estudo e pode ser fomentada através da construção de materiais de autoestudo de qualidade e da comunicação bidirecional a distância.

2. O prazer intelectual e a motivação para a aprendizagem favorecem a consecução dos objetivos de aprendizagem e o recurso a processos e métodos de estudo adequados. (HOLMBERG, 1995, p. 2)

Nessa direção, entendemos que a conversa mediada pode e deve ser conduzida com o uso de um material didático que dê suporte ao processo educativo. Ressaltamos que o material didático impresso operacionaliza as atividades de ensino dando suporte a interação entre aluno e professor criando situações de ensino e pesquisa. Ainda em Holmberg:

A ênfase de sua teoria recai na maneira como o conteúdo do curso é apresentado, no estabelecimento de uma boa relação de conversação entre o aprendiz e o tutor, na criação de uma estrutura administrativa que dê suporte adequado ao desenvolvimento do curso e na escolha de meios mais apropriados para que o aprendiz possa usufruir da relação com o tutor e com o suporte administrativo do curso. (HOLMBERG, 1995, p. 2, grifo meu)

As variedades linguísticas e as diferentes situações comunicativas devem ser consideradas na elaboração do material didático impresso para que as diferentes formas de manifestação da autonomia dos alunos sejam contempladas. As especificidades de cada situação de ensino e aprendizagem e o intercâmbio com as tec- nologias da informação devem promover estratégias de natureza cognitiva e de interação social. A estética do material também deve ser priorizada para garantir a interação entre aluno e conteúdo. O aluno aprende através da construção e reconstrução permanente do conhecimento. Também a interdisciplinaridade deve ser sustentada na transmissão do conteúdo no material didático impresso para promover a reflexão crítica do aluno. O aluno, como um interlocutor da mensagem veiculada no texto impresso percebe a informação a partir de suas experiências individuais e, sobretudo, vivências sócio culturais. Com isso, desenvolve competências diversas que contribuem para um comportamento autônomo. A autoaprendizagem é de cunho pessoal e coletivo, na medida em que o aluno assume um compromisso consigo mesmo e com a instituição ao qual está vinculado. Perceber o aluno como condutor de seu processo de formação implica em promover estratégias de ensino que abarquem as diversas modalidades e ritmos de aprendizagem.

Ainda, na perspectiva da Conversação Didática Guiada de Holmberg (1995), a efetividade do ensino está relacionada diretamente com a maneira como o conteúdo do curso a distância é apresentado e os meios que se utilizam para que o processo de ensino e aprendizagem ocorra de fato. O que importa é que o material didático impresso seja elaborado com intenção de estabelecer o desempenho autônomo do aluno, tendo como base as múltiplas situações de aprendizagem. Fato é que o aluno está em permanente formação de suas capacidades cognitivas.

Sobre a confecção do material didático impresso é importante ressaltar que a instituição de ensino deve selecionar especialistas que dominem o conteúdo a ser trabalhado, para que haja garantia de uma boa veiculação de ideias 
e disseminação do conhecimento. Preti (2009) destaca algumas dificuldades no momento da elaboração que podem influenciar de maneira negativa no processo de aprendizagem do aluno. Dentre estas dificuldades apresentamos:

a) A textualidade: textos com falhas na coerência, na coesão e na argumentação. Textos com pouca clareza, devido não somente à construção de longos parágrafos como, sobretudo, à lógica pouco clara na estrutura das unidades, dos tópicos e dos subtópicos ou na falta de conexão entre os temas desenvolvidos.

b) Na proposta de avaliação de aprendizagem: as atividades elaboradas no material didático nem sempre possibilitariam ao estudante verificar, no processo de leitura, seu nível de compreensão [...].

c) $\mathrm{Na}$ redação adequada de objetivos de aprendizagem: eram propostos objetivos de ensino, daquilo que o professor pretende ensinar e não do que espera o aluno alcançar por meio do estudo das temáticas propostas. [...]

d) Outra dificuldade que emergiu dos textos lidos foi referente à dimensão dialógica, uma característica marcante do material didático na EaD. Diversos professores autores têm compreendido a chamada 'dialogicidade' como a simples abertura do texto com uma saudação ao leitor: 'Prezado estudante', ou propondo paradas de reflexão em algumas passagens do texto: 'O que você acha?', ou 'Agora é com você'. (PRETI, 2009, p. 18-19)

Com base nos argumentos anteriores, cabe destacar que o material didático impresso para EaD não deve ser simplesmente um instrumento de arrolamento de informações. Ao contrário, deve ser concebido como um elemento mediador da prática pedagógica com propósitos e intencionalidades voltadas para o estabelecimento da autonomia do aluno.

O material didático impresso deve sustentar o projeto educativo pressupondo a ação direta do aluno sobre seu processo de aprendizagem. O conceito de autonomia do aluno pressupõe que os alunos têm capacidades diferentes para tomarem decisões a respeito de seus percursos de aprendizagens (MOORE; KEARSLEY, 2010).

\section{Conclusões}

A educação a distância é uma modalidade de ensino que trata de teorias, concepções e metodologias que desafiam o educador, a instituição de ensino e o aluno a assumirem uma posição autônoma no processo educativo. O principal desafio para os professores é possibilitar ao aluno transformar o conhecimento em ação. O aluno deve se responsabilizar pelo processo de ensino e aprendizagem e ter a seu dispor recursos tecnológicos e humanos que dêem suporte a sua formação. Além disso, a educação a distância é uma modalidade de ensino em crescente desenvolvimento e, portanto, se faz necessário criar estratégias pedagógicas eficazes capazes de atender as suas especificidades. Dentre as especificidades, encontramos a elaboração do material didático impresso que deve partir de um modelo pedagógico que promova a autonomia, a colaboração e a interatividade no ensino. Para que o aluno possa construir sua autonomia durante o processo de ensino e aprendizagem em EaD é necessário que o material didático seja avaliado continuamente. Esta avaliação contínua sobre o material didático dará oportunidade de utilizar outros meios para suprir a lacuna detectada no conteúdo disponibilizado no MDI. O professor pode utilizar textos complementares e demais recursos da tecnologia da informação e comunicação como chats, fóruns, vídeos e wikis, dentre outros recursos, para complementar ou ampliar o estudo oferecido no MDI. 
É importante destacar que o fundamental é elaborar um material didático que promova a interação entre o aluno e o conteúdo para facilitar a apropriação do conhecimento e possibilitar o desenvolvimento da autonomia. O material didático deve despertar no aluno a automotivação e ter como base o paradigma da autoformação / autonomia. No ensino a distância o material didático é considerado apoio prioritário ao estudo e deve ser confeccionado com vistas a atender a filosofia educacional do curso. Contudo, no reverso ao que foi discutido neste estudo, nem todos os alunos são autônomos, como nem todos os alunos possuem grau de autonomia necessária para conduzir com eficiência seu percurso de aprendizagem. A partir desta afirmação propomos a criação de materiais didáticos que impeçam um ensino mnemônico para garantir o desenvolvimento de competências necessárias para o estabelecimento de uma atitude autônoma, na interação com o conhecimento, com os professores e com os colegas de curso. O uso do material didático deve proporcionar ao aluno atitudes de trabalho autoral que potencializem a autonomia tão necessária a sua inserção na sociedade do conhecimento. Relacionando os demais estudos dos integrantes do grupo com a questão da autonomia, conclui-se que os responsáveis pela elaboração do MDI devem priorizar a construção de textos simples, baseados no princípio da interação ou do diálogo, objetivando uma clara recepção de informação pelos alunos.

\section{Referências}

BARRETO, C.C. Desenho Instrucional em Materiais Didáticos Impressos: uma boa ideia. In: BARRETO, C.C. et al. (Org.). Planejamento e Elaboração de Material Didático Impresso Para Educação a Distância. Rio de Janeiro: Fundação CECIERJ, 2007. 291 p.

BELLONI, M.L. Educação a Distância. Campinas: Autores Associados, 1999.

HOLMBERG, B. Theory and practice of distance education. Londres: Routledge, 1995.

MOORE, M.; KEARSLEY, G. Educação a Distância: uma visão integrada. São Paulo: Cengage Learning, 2010.

PRETI, O. Material Didático Impresso na EaD: experiências e lições apre(e)ndidas. [S.I.: s.n.], 2009. Texto apresentado no III Encontro Nacional de Coordenadores UAB e I Encontro Internacional do Sistema Universidade Aberta do Brasil, 2009, Brasília, BR-DF. Disponível em: <http://www.uab.ufmt.br/uab/images/ artigos_site_uab/material_didatico_impresso_ead.pdf> Acesso em: 3 nov. 2011.

SILVA, A.V.M. Autonomia Como Princípio Educativo: reflexões a partir das teorias pedagógicas no contexto educacional brasileiro entre os séculos XIX e XX. 2009. Dissertação (Mestrado em Educação) 
- Programa de Pós-Graduação em Educação, Universidade Federal do Estado do Rio de Janeiro, 2009, Rio de Janeiro, BR-RJ.

SILVA, M. Pedagogia do Parangolé: novo paradigma em educação presencial e on-line. [S.I.: s.n.], 2003. Disponível em: <http://www.saladeaulainterativa.pro.br/texto_0004.htm> Acesso em: 3 nov. 2011.

VALENTE, J.A.; MORAN, J.M. Educação a Distância: pontos e contrapontos. São Paulo: Summus, 2011.

VIEIRA, F. Pedagogy for autonomy: exploratory answers to questions any teacher should ask. In: MÜLLERVERWEYEN, M. (Ed.). Standpunkte zur Spracht-und Kulturvermittlung 7: Neues lernen, Selbstgesteuert, Autonom. München: Goethe Institut, 1997. P. 53-72.

Submetido para avaliação em 28 de junho de 2013.

Aprovado para publicação em 14 de junho de 2014.

Andréa Villela Mafra da Silva: Universidade Federal do Rio de Janeiro - Rio de Janeiro - RJ - Brasil. Email: av.mafra@hotmail.com 